\title{
The Aquatic Conservation Network Introduces Its Affiliate Club Programme
}

$\mathrm{T}$ The Áquatic Conservation Network (ACN) recently initiated the Affiliate Club Program. In the few months since its inception, the programme has already attracted 11 affiliates from different parts of the globe (Australia, France, UK, \& USA). The Affiliate Club Program is targeted at amateur aquarist societies and is designed to:

- Instill a sense of stewardship into fish-keeping;

- Encourage proper and optimum care of aquarium fish;

- Intensif $y$ the focus on the conservation of aquatic biodiversity; and

- Foster initiatives aimed at preventing the extinction of freshwater fish species.

Societies joining the programme agree to foster certain goals and attitudes, through there is no expectation for immediately implementing all of the objectives. By joining the ACN Affiliate Club Program, societies agree to discuss the goals on an ongoing basis and continually strive to make them part of their membership's approach to keeping fish.
A copy of the affiliation agreement follows this note, and you are encouraged to contact either of the following if you have any questions or are otherwise interested:

RODNEY W. HARPER, Affiliate Club Liaison
Aquatic Conservation Network
li450 Boe Road Ext.
Grand Bay, Alabama 36541, USA
Phone/Fax: 334-865-6987
Internet: Elassoma@cris.com
CompuServe: 75130,1321

$\&$

Roв HunTLEy, General Manager

Aquatic Conservation Network

540 Roosevelt Avenue

Ottawa, Ontario K2A 1Z8, Canada

Tel: (613) 729-4670; Fax: (613) 729-5613

Internet: ag508@ freenet. carleton.ca

CompuServe: 71022,3537

\section{Aquatic Conservation Network: Affiliate Clubs Programme}

Affiliate clubs (see above) agree to foster the following goals and attitudes:

1. Recognize that conservation efforts are sustained by a sincere respect for the living creatures that share the planet with us, combined with a desire to help preserve them.

2. Encourage long-term breeding practices that maintain species for several generations. Organize breeder award programmes that reward the aquarist who keeps and breeds a species for many years.

3. Make every effort to ensure that wild fish are obtained legally and that purchasing or collecting wild fish does not put increased pressure on endangered fish in the wild. The purchase of captive-bred fish is encouraged.

4. Keep only those fish that can be cared for properly, giving each fish the space necessary to grow to its maximum size while maintaining optimum health and life-span.

5. Learn how to breed fish in a manner that helps to maintain genetic diversity and encourage Club members to put this knowledge into practice in their breeding programmes.

6. Breed fish in such a way that they maintain the characteristics of the species as found in Nature and avoid breeding for distortions in colour, shape, fin size, etc. Selective breeding for certain colour and body characteristics is understood to be commonplace and acceptable in some hobby and research activities. However, species assigned to conservation breeding programmes are not to be selectively bred in this fashion.

7. Learn as much as possible about the natural habitat of the fishes that interest Club members and alert others if there is any threat of extinction.

8. Sponsor at least one conservation-oriented programme a year and, when possible, provide financial support for in-situ or ex-situ conservation programmes. Move in the direction of developing more Conservation Aquarists in the Club.

9. Never dispose of fish or other aquatic animals by 'dumping' them into waters that are not part of their natural habitat. Further, fish and other aquatic animals are not to be released into waters that are part of their natural habitat, except when part of an official conservation restocking programme.

10. When the Club, or a group within the Club, feels it is ready to commit itself to the discipline of long-term conservation efforts, volunteer to join one of the $\mathrm{ACN}$ captive breeding programmes.

\section{(Concluded from page 366 )}

long does it take to kill (hours or days), and how long does it persist (weeks or months)? Answers to these questions are relatively easy to obtain. The level of ecological knowledge about AcNPV (and similar NPVs) is probably about the same as it was when DDT was first tested and declared a safe and effective pesticide! However, as is now well-known, the harmful and 'unexpected' effects of DDT took a long time to emerge and could never have been elucidated from short-term field trials. No one had the remotest idea that the numbers of birds of prey would decline (of some species drastically) as a consequence of DDT transfer and its accumulation in food-webs.

This leads me to my last point: is there a need for such high-tech pesticides? In Britain, farmers are currently paid for 'set aside' land on which no crops are allowed to be grown, at least for a certain period of time, and similar schemes operate elsewhere in Europe and America. The entire philosophy of the advocates of biopesticides assumes a continuing commitment to monocultures and genetic uniformity of crops, and certainly not to a redesigning of agriculture with less monoculture and more genetic diversity. In other words the problem of pests is approached in terms of how best to kill them, and not of how best to prevent them from building up in numbers and evil influence in the first place. In my view, the need for genetically modified NPVs is about as great as the need to test atom bombs on Pacific Ocean atolls.

$$
\text { REFERENCES }
$$

CoRY, J.S. (1994). First field trial of a genetically improved baculovirus insecticide. NERC News, July, pp. 18-20.

Cory, J., Hirst, M., Williams, T., Hails, R., Goulson, D., GreEn, B., Carty, T., Possee, R., CAYley, P. \& Bishop, D. (1994). Field trial of a genetically improved baculovirus insecticide. Nature (London), 370, pp. 138-40.

LEVIDOW, L. (1995). The Oxford baculovirus controversy - safety testing safety? BioScience, 45 , pp. 545-51.

OwEN, D.F. (1994). Trouble in the cabbage-patch. Environmental Conservation, 21, pp. 102-3.

DENIS F. OWEN

School of Biological and Molecular Sciences

Oxford Brookes University

Headington

Oxford $O X 3 O B P$

England, $U K$. 